\title{
AIRWAY CLOSURE IN PREGNANCY
}

\author{
Douglas B. Craig and M.A. Toole
}

\section{INTRODUCTION}

Arterial hypoxaemia during pregnancy in otherwise normal women is an infrequent, but clinically important finding. Although most studies have found the arterial oxygen tension $\left(\mathrm{Pa}_{\mathrm{O}_{2}}\right.$ ) during pregnancy to be normal or increased, ${ }^{1,2}$ some have found abnormally low values in some patients, without apparent cause. ${ }^{3-5}$ Ang, et al. found a large reduction in $\mathrm{Pa}_{0_{2}}$ associated with a change from the seated to the supine position in late pregnancy. ${ }^{6}$ The mechanisms producing these abnormalities have not been established.

Airway closure may be one factor producing arterial hypoxaemia in some parturients. In ten of twenty hospitalized pregnant women near term, Bevan, et al. found that the closing capacity (CC) ${ }^{\circ}$ exceeded functional residual capacity (FRC). ${ }^{8}$ We have previously shown this relationship of CC to FRC to be associated with an enlargement of the alveolar-arterial oxygen gradient. ${ }^{9}$ This effect on gas exchange was thought to be the result of impairment of ventilation to areas in which airway closure was occurring, leading to low ventilation perfusion $(\mathrm{V} / \mathrm{Q})$ ratios in affected areas.

The reduction in FRC that is a characteristic finding in pregnancy ${ }^{10}$ is also likely an important factor leading to abnormal gas exchange. The combination of a reduced FRC and an increased CC would result in a CC which exceeded FRC in some subjects, leading to impairment of gas exchange.

To the present, there has been no systematic study of CV in the same subjects during pregnancy and post partum. Bevan, et al. ${ }^{8}$ measured CC on one occasion in a group of pregnant subjects, but did not measure FRC and RV. We have measured $\mathrm{CV}, \mathrm{CC}$, and standard lung volumes serially during pregnancy and post partum during uncomplicated pregnancies in healthy parturients.

\section{MeTHods}

Twenty-four pregnant subjects 21 to 29 years of age were studied at approximately 4-week intervals from the time of entry into the study ( 18 to 25 weeks gestation) until delivery. Twelve were asymptomatic cigarette smokers, 12 were

From the Department of Anaesthesia, Health Sciences Centre, University of Manitoba, 700 William Avenue, Winnipeg, Manitoba, Canada.

Supported by the Medical Research Council of Canada.

${ }^{\circ} \mathrm{CC}$ is "the lung volume at which the dependent lung zones cease to ventilate, presumably as a result of airway closure."? CC is obtained by the addition of closing volume (CV) and residual volume ( $R V$ ). CV is measured during a vital capacity (VC) expiration and is expressed as a percent of $\mathrm{VC}$, or as a lung volume above $\mathrm{RV}$.

Canad. Anaesth. Soc. J, vol. 22, no. 6, November 1975 
non-smokers. Subjects with respiratory or cardiovascular symptoms or abnormalities were not included. All pregnancies were single and there were no significant obstetrical complications. The protocol for this study was approved by the Faculty Committee on the Use of Human Subjects in Research. Subjects agreed to participate following full explanation of the nature and purpose of the study. Studies were performed on each subject on three to six occasions during pregnancy and once on all 24 subjects between six and eight weeks post partum. For analysis and presentation, as outlined in Table I, data has been grouped according to gestation into six study periods.

TABLE 1

\begin{tabular}{|c|c|c|}
\hline $\begin{array}{l}\text { Study } \\
\text { period }\end{array}$ & $\begin{array}{l}\text { Weeks } \\
\text { gestation }\end{array}$ & $\begin{array}{l}\text { Number of } \\
\text { subjects }\end{array}$ \\
\hline 1 & $18-21$ & 13 \\
\hline 2 & $22-25$ & 21 \\
\hline 3 & $26-29$ & 23 \\
\hline 4 & $30-33$ & 18 \\
\hline 5 & $34-37$ & 22 \\
\hline 6 & $38-41$ & 10 \\
\hline
\end{tabular}

$\mathrm{CV}, \mathrm{FRC}$, and remaining standard lung volumes were measured while subjects lay supine with their heads raised on a pillow and while they sat upright in a straight-backed chair. The sequence of testing was varied in a random fashion. A delay of at least five minutes was allowed between FRC and CV measurements.

$\mathrm{CV}$ was measured by the single-breath nitrogen method, as in our previous studies. ${ }^{11}$ Since the completion of this study, suggested standardized procedures for the measurement of closing volume by the nitrogen method have been published. ${ }^{12}$ While our apparatus did not entirely meet the suggested design, we have followed the recommended criteria for acceptability and analysis of the closing volume tracings. FRC was measured by the closed-circuit helium technique, as in our previous studies. ${ }^{11}$

The post partum study period was considered as the control period. Analysis was by a paired T-test, so that data in each study period were compared with matched data for the same subjects in the control period. Data were analyzed with all 24 subjects grouped together, and also separated as to smoking history. In addition, data from the seated and supine positions were compared for the 24 subjects. A p-value of 0.05 or less was considered significant.

\section{Results}

Mean results ( \pm Standard Error) for each of the six study periods are summarized in Tables II and III. With the exception of CV and the difference between FRC and CC (FRC-CC) all other results are expressed as a percentage of the post partum control values. Because they lose meaning when expressed as per cent of control, CV and FRC-CC results are indicated in absolute numbers, with both 


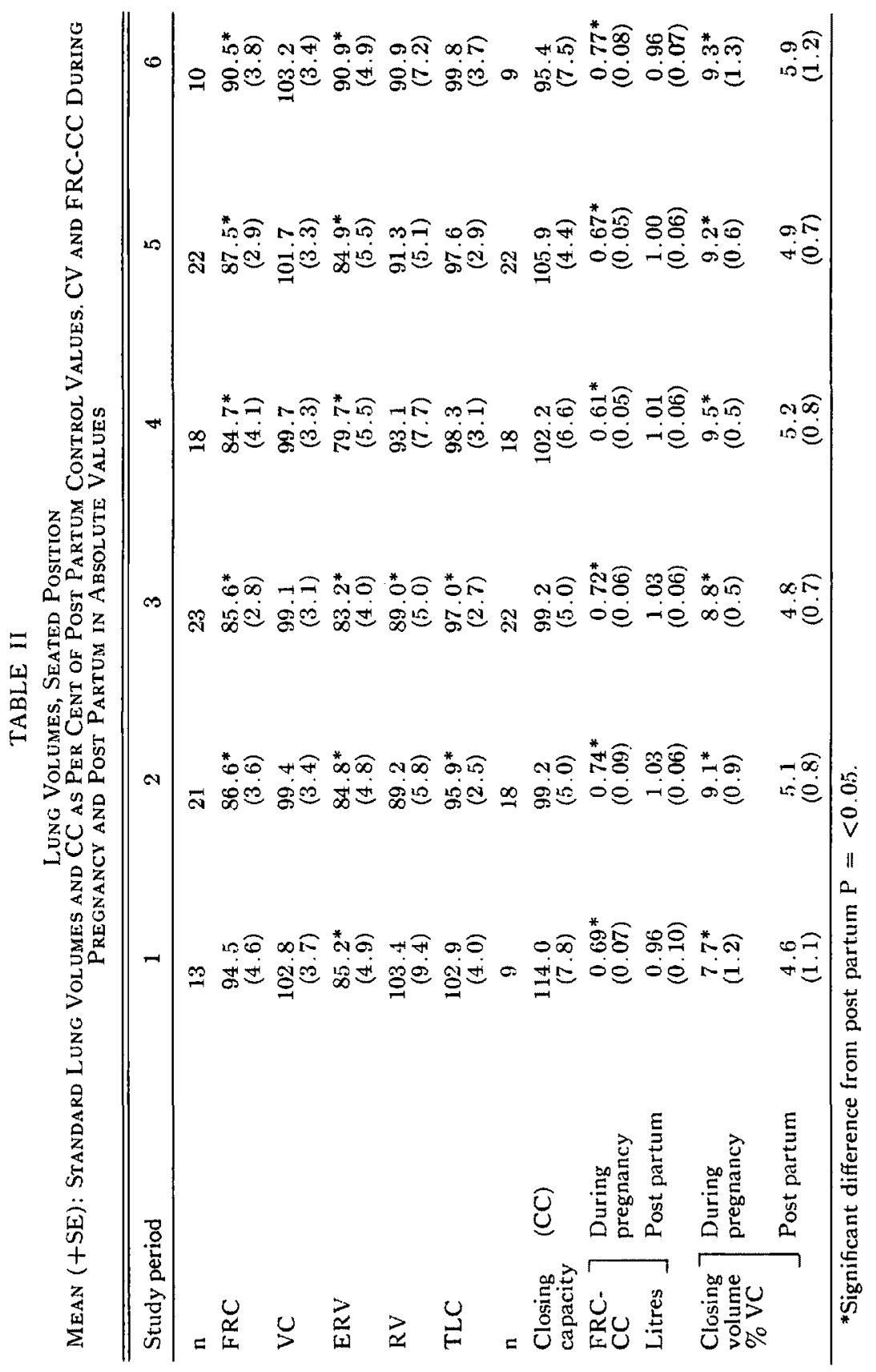




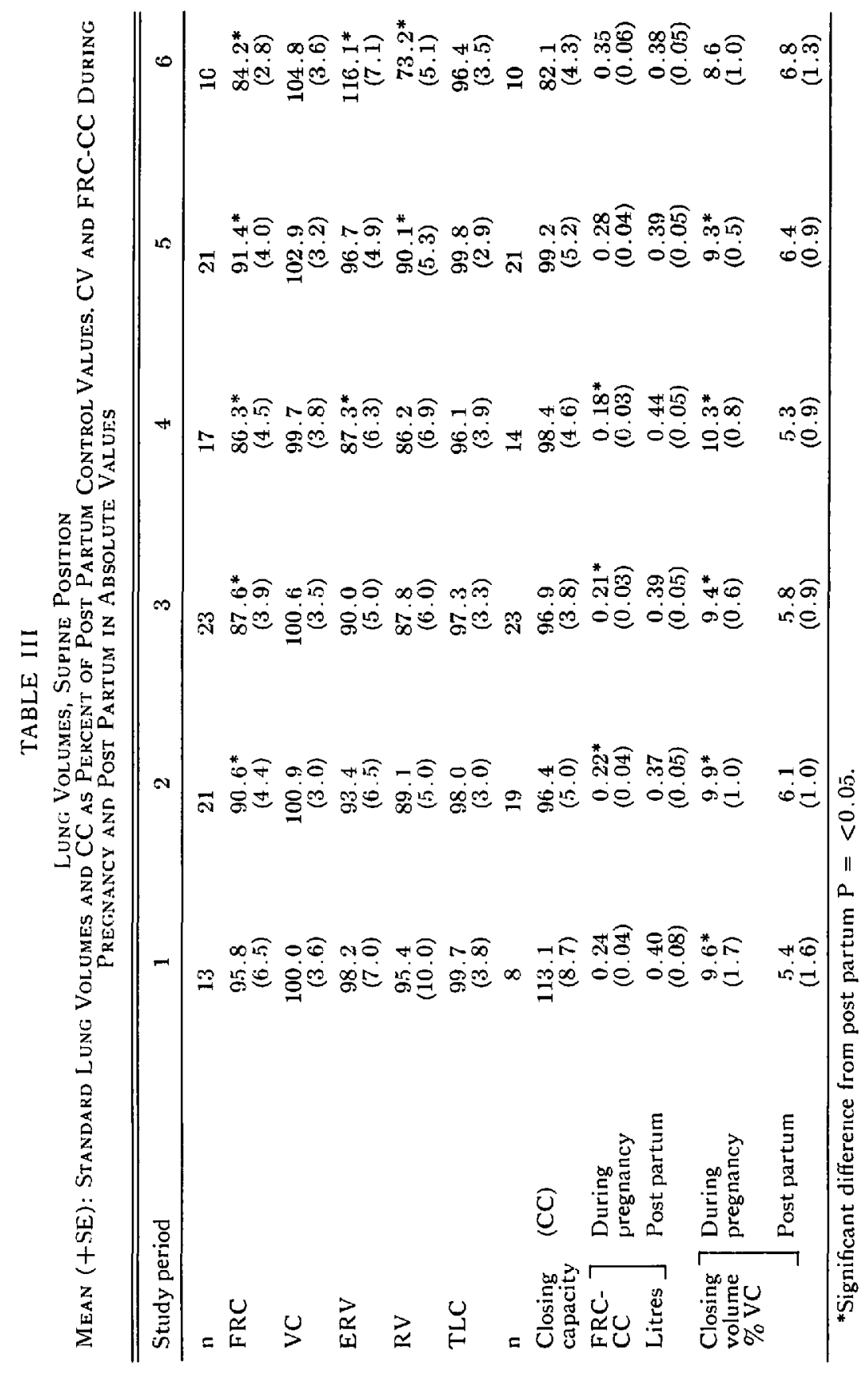


the pregnancy values and post partum control values included. Since in any given study period acceptable data for lung volume and airway closure measurements were not obtained for all subjects, there are differences in the number of observations $(n)$ between these categories. Statistical significance $(P=<0.05)$ is indicated by an asterisk.

CV was significantly increased in seated subjects in all six study periods and in all but the last study period in the supine position. However, $\mathrm{CC}$, which is a more direct measure of the lung volume at which airway closure was detected, showed no significant difference at any time during pregnancy from non-pregnant control values. The index of the functional consequences of airway closure, FRC-CC, was significantly reduced in upright subjects in all six periods and in three of six when supine. This indicates that airway closure was occurring at a lung volume closer to FRC during pregnancy. In none of the 24 seated subjects did CC exceed FRC during pregnancy and in only two subjects was this observed in the supine position.

The most important changes in standard lung volumes were the significant reductions in FRC in both seated and supine subjects in all but the initial study period. VC was unchanged throughout pregnancy, a factor important because of the expression of $\mathrm{CV}$ as a percentage of VC. RV tended to be reduced, but this reduction rarely achieved statistical significance. Because $\mathrm{CC}$ is obtained by the addition of $\mathrm{RV}$ to $\mathrm{CV}$, the observed small reduction in $\mathrm{RV}$ becomes important in understanding why $\mathrm{CC}$ did not change, as will be discussed later.

Analysis of data with subjects separated according to smoking history did not reveal any important differences as compared to the combined group analysis. Notably, CV and CC changes were not different in the two groups.

When data for all subjects in the seated and supine positions were analyzed, significant differences were noted. FRC and expiratory reserve volume (ERV) fell while inspiratory capacity (IC) rose with the change from upright to supine. There was no change with posture in VC, total lung capacity (TLC), RV, CV or CC. The difference between FRC and CC (FRC-CC) was invariably less in the supine position.

\section{Discussion}

The observed changes in standard lung volumes are in agreement with those previously reported. ${ }^{10}$ These changes do not require further discussion except as they relate to the airway closure phenomenon under examination. The closing volume data are largely new and in partial disagreement with the earlier report by Bevan, et al. 8

Examination of the $\mathrm{CV}$ data, in which large and significant increases in $\mathrm{CV}$ (expressed as $\%$ VC) were found, suggests major functional changes occurred during pregnancy. This is not so. CC, which includes both RV and CV, was unchanged throughout pregnancy, allowing us to conclude that airway closure occurred at the same overall lung volume during and following pregnancy. While $\mathrm{VC}$ was unchanged, small decreases in RV were noted, both as previously reported. This reduction in $\mathrm{RV}$ without a change in VC led to the observed increase in CV, even though there was no real change in the lung volume at which airway closure was detected. The explanation for these confusing findings is illustrated diagramatically in Figure 1. 


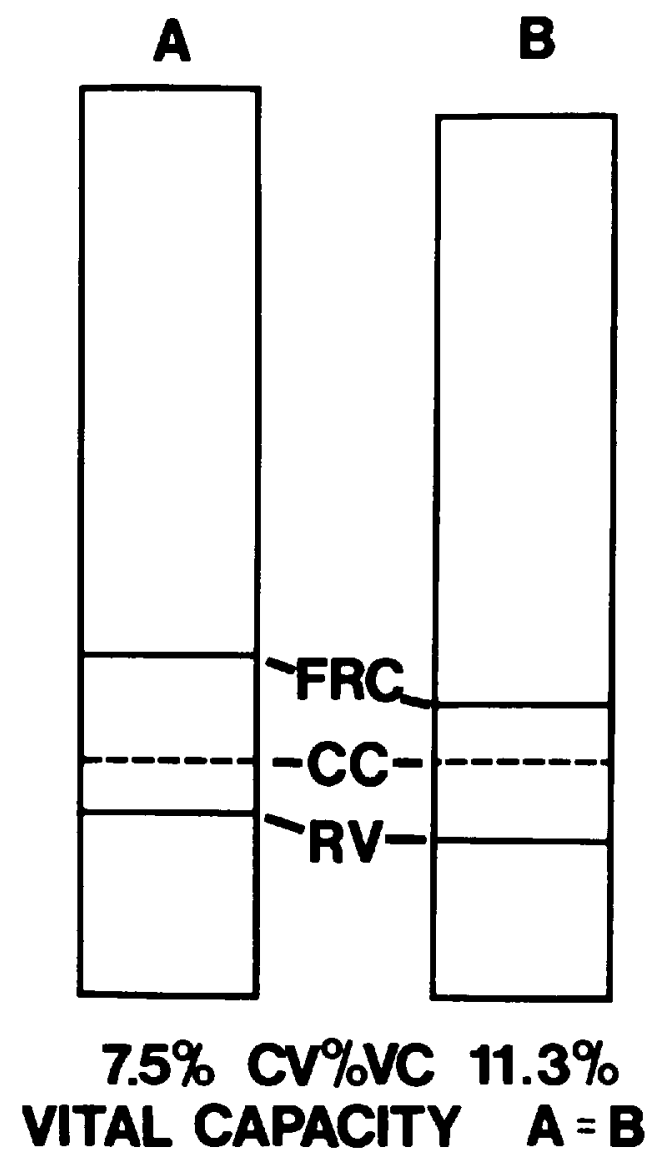

Figure 1. Illustration of mechanism whereby without any change in lung volume at which airway closure was detected (CC), significant increases in $\mathrm{CV}$ expressed as $\% \mathrm{VC}$ occurred during pregnancy ( Panel B) as compared to Post Partum (Panel A).

$$
\mathrm{VC}_{\mathrm{A}}=\mathrm{VC}_{\mathrm{B}} \quad \mathrm{RV}_{\mathrm{A}}>\mathrm{RV}_{\mathrm{B}}
$$

Our failure to find any change in CC is not surprising in view of the data of Gee, et al. who found lung compliance to be unchanged during pregnancy. ${ }^{13}$ This indicates that the basic retractive forces of the lung were unchanged and suggests that those forces which tend to maintain small airway patency would also be unchanged. The same authors noted a 50 per cent reduction in airway resistance during pregnancy, but this measurement is an index of large airway dynamics and does not reflect the behaviour of small airways, which is thought to be measured by the closing volume test.

Our most important finding was the reduction in FRC-CC, brought about by the approximately 15 per cent fall in FRC. If we consider the relationship of CC to FRC in an absolute all-or-none fashion, then our data suggest that the phenomenon measured by the closing volume test, presumably airway closure, was of no consequence in our subjects except for the two in whom CC exceeded FRC in the supine position. It does not seem reasonable, however, to consider the closing volume test as measuring an all-or-none phenomenon. Prior to the onset of detectable airway 
closure, narrowing of small airways is likely to occur. Such narrowing would tend to reduce ventilation to affected areas in a similar but less complete fashion than actual closure of airways. The net effect of either narrowing or closure would be the creation of low $\mathrm{V} / \mathrm{Q}$ areas, leading to a reduction in $\mathrm{Pa}_{\mathrm{O}_{2}}$. If this speculation is correct, then any reduction in FRC-CC such as we observed during pregnancy, would, if acting alone, be expected to have an adverse effect on gas exchange. Airway closure is likely therefore to be an important mechanism producing changes in $\mathrm{V} / \mathrm{Q}$ relationships in the lung during pregnancy.

Our failure to find a larger $\mathrm{CV}$ in cigarette smokers is in contrast to previous studies, ${ }^{14}$ and is likely due to the small number and young ages of our subjects.

We observed a significant reduction in FRC-CC in the supine position. as compared to upright, again emphasizing the important effect of posture on this relationship. ${ }^{9}$ This offers one explanation for the observations of Ang, et al. who found a mean reduction in $\mathrm{Pa}_{0_{2}}$ of 13 torr in a group of pregnant women following a change from the seated to the supine position. ${ }^{6}$ We have not confirmed the observations of Bevan, et al. who found that $\mathrm{CC}$ was above FRC in ten of twenty seated women near term. ${ }^{8}$ In none of our seated subjects did we find this relationship. This difference in results may be due to differences in measurement techniques or in the population studied. Eight of Bevan's subjects were older than our oldest subject. Closing volume increases with age, so a small increase due to this factor would be expected. It would have been preferable for our study to have included some older subjects. In addition, several of Bevan's subjects were hospitalized for obstetrical complications, including pre-eclampsia, and so cannot be considered representative of normal subjects.

We have found clinically important changes in the relationship of CC to FRC during pregnancy. FRC-CC was significantly reduced as compared to the post patum control period in both seated and supine subjects. This resulted from a decrease in FRC in the presence of an unchanged CC. This finding suggests that airway closure is likely to be one mechanism influencing $V / Q$ relationships, and so arterial oxygenation during pregnancy. Physicians caring for patients during pregnancy are reminded that significant abnormalities of $\mathrm{Pa}_{0}$ may be present in otherwise normal women.

\section{SUMMARY}

Closing capacity (CC; the lung volume at which dependent lung zones cease to ventilate, presumably as a result of airway closure) and standard lung volumes were measured in twenty-four normal women 21 to 29 years of age in the seated and supine positions. Measurements were made serially during pregnancy and once 6 to 8 weeks post partum (the control period). CC was unchanged during pregnancy, while functional residual capacity (FRC) fell by approximately 15 per cent. The difference between FRC and CC (FRC-CC) was reduced during pregnancy, but in one of the subjects when seated, and in only two supine subjects did CC exceed FRC. FRC-CC was reduced in the supine position as compared to seated. The reduced FRC-CC during pregnancy offers a potential explanation for the observations of abnormally low arterial oxygen tensions $\left(\mathrm{Pa}_{\cap_{2}}\right)$ during pregnancy in some women, and of reduced $\mathrm{Pa}_{0}$ in pregnant women in the supine as compared to upright position. 


\section{RÉsUMÉ}

La capacité de fermeture (volume où les parties déclives du poumon cessent d'être ventilées, présumément par fermeture des voies aériennes) et les volumes pulmonaires standards ont été mesurés chez 24 femmes normales âgées de 21 à 29 ans, en position assise et couchée. Ces mesures ont été effectuées de façon sériée pendant la grossesse, et durant six-huit semaines en post-partum (période contrôle). La capacité de fermeture demeure inchangée durant la grossesse, alors que la FRC chute de 15 pour cent environ. L'écart entre la capacité de fermeture et la FRC (FRC-CC) est réduit durant la grossesse; chez l'une de ces patientes, en position assise, et chez deux autres en position couchée, la capacité de fermeture a excédé la FRC. La réduction de cet écart est plus importante en position couchée qu'en position assise. La réduction de l'écart entre la FRC et la capacité de fermeture, durant la grossesse, est une explication possible de la diminution de la tension en Oxygène du sang artériel $\left(\mathrm{Pa}_{\mathrm{O}_{2}}\right)$ observée durant la grossesse chez certaines patientes, et de la diminution de la $\mathrm{Pa}_{\mathrm{O}_{2}}$ chez la femme enceinte en position couchée, comparée à la position debout.

\section{ACKNOWLEDGMENT}

The advice and assistance of Mrs. Pat Moodie and Mr. Bob Rollwagen, Computer Department for Health Sciences, University of Manitoba, is gratefully acknowledged.

\section{REFERENCES}

1. Fisher, A. \& Prys-Roberts, C. Maternal pulmonary gas exchange. A study during normal labour and extradural blockade. Anaesthesia 23: 350-356 (1968).

2. ANDERSON, G.J. \& WALKER, J. The effect of labour on the maternal blood-gas and acidbase status. J. Obstet. Gynaec. Brit. Com. 77: 289-293 (1970).

3. Stengen, V., EmzMan, D., Andersen, T., et al. Observations on the placental exchange of the respiratory gases in pregnant women at Cesarean section. Amer. J. Obstet. Gynec. 88: $45-57$ (1964).

4. Lucius, H., Gahlenbeck, H., Kleine, H.O., et al. Respiratory functions, buffer system, and electrolyte concentrations of blood during human pregnancy. Resp. Physiol. 9: 31]$317(1970)$.

5. Houle, G.L., Fox, G.S., \& Gertel, M. Methoxyflurane: clinical and laboratory studies during Cesarean section. Anesth. Analg. (Cleveland) 48: 1011-1017 (1969).

6. ANG, C.K., TAN, T.H., Walters, W., et al. Postural influence on maternal capillary oxygen and carbon dioxide tension. Brit. Med. J. 4: 201-203 (1969).

7. Leblanc, P., Ruff, F., \& Milic-EMmi, J, Effects of age and body position on "Airway closure" in man. J. Appl. Physiol. 28: 448-451 (1970).

8. Bevan, D.R., Holdcroft, A., Lom, L., et al. Closing volume and pregnancy. Brit. Med. J. 1: $13-15$ (1974).

9. Craic, D.B., Wahba, W.M., Don, H.F., et al. "Closing volume" and its relationship to gas exchange in seated and supine positions. J. Appl. Physiol. 31: 717-721 (1971).

10. Phowse, C.M. \& Gaensler, E.A. Respiratory and acid-base changes during pregnancy. Anesthesiology 26:381-392 (1965).

11. Chaig, D.B. \& McCarthy, D.S. Airway closure and lung volume during breathing with maintained airway positive pressures. Anesthesiology 36: 540-543 (1972).

12. Suggested standardized procedures for closing volume deterninations (nitrogen method). Division of Lung Diseases, National Heart and Lung Institute. Bethesda, Maryland, July, 1973.

13. Gee, J.B.L., Packer, B.S., Millen, J.E., et al. Pulmonary mechanics during pregnancy. J. Clin. Invest. 46: 945-952 (1967).

14. Buist, A.S. \& Ross, B.B. Quantitative analysis of the alveolar plateau in the diagnosis of early airway obstruction. Am. Rev. Resp. Dis. 108: 1078-1087 (1973). 